\title{
Impactos ambientais da ocupação urbana do igarapé Tucunduba
}

\author{
Fernando Cardoso de Matos ${ }^{1}$ \\ Marcelo dos Santos Targa ${ }^{2}$ \\ Getulio Teixeira Batista ${ }^{2}$ \\ Nelson Wellausen Dias ${ }^{2}$ \\ ${ }^{1}$ Universidade de Taubaté - UNITAU \\ Mestrando em Ciências Ambientais. Estrada Mun. Dr. José Luiz Cembranelli, 5.000- 12080- \\ 010 - Taubaté - SP, Brasil \\ matos2001@gmail.com.br \\ ${ }^{2}$ Professor do Programa de Pós-Graduação em Ciências Ambientais da Universidade de \\ Taubaté - UNITAU \\ Estrada Mun. Dr. José Luiz Cembranelli, 5.000- 12080-010 - Taubaté - SP, Brasil \\ \{targa.marcelo, gtbatista $\} @$ gmail.com \\ nwdias@gmail.com
}

\begin{abstract}
This paper presents an assessment of the environmental degradation of the stream Tucunduba in Belém do Pará. The basin is situated in an area of accelerated process of urbanization and is now occupied by low-income population and lacks infrastructure services. The Tucunduba stream is located southeast of the city of Belém and has $3900 \mathrm{~m}$ of extension and its basis has about 1055 ha in area and it is a tributary of the large rio Guama. The analysis of ortho-rectified aerial photos obtained in 1972, 1977 and 1998 and of a SPOT satellite imagery obtained in 2006 using computational tools of ArcMap and ArcGIS packages it was possible to produce maps showing the accelerated urbanization in the region around the stream and as a consequence the decrease in green area. Based on field check, it was possible to verify the major environmental impacts caused by inappropriate human occupation of this area, confirming poor sanitation conditions and the disposal of waste directly in the water body without any treatment.
\end{abstract}

Palavras-chave: Bacia hidrográfica, igarapé, urbanização acelerada, impacto ambiental, land use, urbanization, temporal analysis.

\section{Introdução}

No Globo terrestre, praticamente não existe um ecossistema que não tenha sofrido influência direta e/ou indireta do homem, como por exemplo, contaminação de lençol freático, contaminação dos ambientes aquáticos, desmatamentos, diminuição da biodiversidade de habitats, e introdução de espécies exóticas (GOULART; CALLISTO, 2003). Os processos de degradação ambiental, em consequência do crescimento das cidades, de certo modo, refletem a forma como a sociedade se apropria da natureza. Com o desenvolvimento do capitalismo, a partir da segunda metade do século XX, houve um crescimento acelerado da população em geral, agravado por forte processo migratório de pessoas do campo para as cidades resultando em sérios problemas sociais urbanos (FERREIRA, 1995).

Segundo o CONAMA (1986) considera-se impacto ambiental qualquer alteração das propriedades físicas, químicas e biológicas do meio ambiente, causada por qualquer forma de matéria e energia resultante das atividades humanas que, direta ou indiretamente, afetam: a saúde, a segurança e o bem-estar da população, as atividades sociais e econômicas, a biota, as condições estéticas e sanitárias do meio ambiente e a qualidade dos recursos ambientais. Rohde (2004) caracteriza impacto ambiental como sendo "Mudança sensível, positiva ou negativa, nas condições de saúde e bem estar das pessoas e na estabilidade do ecossistema do que depende a sobrevivência humana. Essas mudanças podem resultar de ações acidentais ou planejadas, provocando alterações direta ou indiretamente". 
Observa-se no igarapé Tucunduba um total descaso com preservação ambiental. A população se instalou na região, provocando impactos ambientais como: erosão, aumento do escoamento superficial, poluição e contaminação da água. No processo, houve aterramento com desvio do curso do rio, lançamento de diversos tipos de sedimentos no curso d'água que provocaram o assoreamento e o aumento do risco de cheias. A devastação de florestas para a construção de moradias, a partir da década de 60 e o mau uso do solo são um dos muitos problemas que contribuíram para intensificar o assoreamento, pois suas margens ficaram desprotegidas e resultaram em um aumento da turbidez do igarapé.

Cursos d'água nas grandes cidades brasileiras são transformados em esgotos a céu aberto, pois, além de transportar as águas pluviais, transportam esgoto sem tratamento, com alta quantidade de contaminantes (PORTO, 1995). A várzea do igarapé Tucunduba tem cerca de $37 \%$ de sua de sua área constituída de terrenos de cota inferior ao da maré máxima de 3,70 m. A pouca navegabilidade que o igarapé apresenta possibilita o intercâmbio da população que mora em suas margens a outras localidades da região.

Na década de 70 houve grandes transformações no contexto político, econômico e social em Belém, e foi a época em que a várzea do igarapé se tornou urbanizada, provocando uma intensa ocupação das planícies, devido à população que migrava para a capital ou que se deslocava dos setores valorizados da cidade. O igarapé Tucunduba é o principal contribuinte da bacia que recebe o mesmo nome, com 3.600 metros de extensão, sendo este curso d'água e seus afluentes os responsáveis pelos alagamentos dos terrenos localizados nos bairros que compõem a referida bacia.

O igarapé Tucunduba tem sua nascente na Travessa Angustura, 3579 entre as Avenidas Almirante Barroso e $1^{\circ}$ de Dezembro (Bairro do Marco) e seu exutório na margem direita do Rio Guamá (Bairro do Guamá), em área da Universidade Federal do Pará, e ao longo de seu percurso recebe dejetos resultantes de atividades antrópicas que tornam o igarapé bastante poluído a ponto de impedir o seu efetivo aproveitamento para uso doméstico (SILVA, 2003).

Grande parte das moradias mais simples é construída sobre os cursos d'água, causando erosão nas margens e lançam seus esgotos diretamente na água, alterando, inevitavelmente, a qualidade do corpo hídrico e, ferindo o Código Florestal referente às Áreas de Preservação Permanente. Alteram ainda o traçado natural do rio, provocam o aumento de sedimento no fundo e com isso um aumento no escoamento superficial. Encontram-se no Tucunduba madeireiras, vendedores de açaí, entre outros serviços, que lançam resíduos diretamente no corpo hídrico. Dessa forma, esse igarapé tem um enorme potencial para veiculação de inúmeras doenças.

Esse artigo apresenta uma análise dos impactos ambientais ocasionados pelo processo de urbanização nas margens do igarapé Tucunduba, com base em geotecnologias que utilizam Sistemas de Informações Geográficas (SIG).

\section{Material e Métodos}

\subsection{Localização da área de estudo}

O presente trabalho foi realizado no município de Belém, Pará, no igarapé Tucunduba. A cidade de Belém tinha 1.279.861 de pessoas, segundo o censo do IBGE (2000) e uma área territorial de $1065 \mathrm{~km}^{2}$. As coordenadas centrais da cidade são $1^{\circ} 20^{\prime} \mathrm{S}$ e $48^{\circ} 30^{\prime} \mathrm{W}$, em uma altitude de 15 metros em relação ao nível do mar.

A Bacia do Tucunduba é composta por 13 canais, com 14.175 metros, sendo estes: o Igarapé Tucunduba, Lago Verde, Caraparú, 2 de Junho, Mundurucus, Gentil Bittencourt, Nina 
Ribeiro, Santa Cruz, Cipriano Santos, Vileta, União, Leal Martins e Angustura. O Tucunduba é o principal igarapé da Bacia, com 3.600 metros de extensão, sendo este curso d'água e seus afluentes os responsáveis pelos principais alagamentos dos terrenos localizados nos bairros que compõem a referida bacia (PMB, 2000). Sua foz está localizada nas coordenadas $1^{\circ} 27^{\prime} \mathrm{S}$ e $48^{\circ} 27^{\prime} \mathrm{W}$ (Figura 1) e a sua bacia possui 1.055 ha, sendo cerca de 575 ha em áreas de "baixadas", correspondendo a 21,02\% das áreas de várzea de Belém.

Segundo Köppen, o clima de Belém é quente e úmido, com temperatura média de $26^{\circ} \mathrm{C}$, mínima de $20^{\circ} \mathrm{C}$ e máxima de $38^{\circ} \mathrm{C}$. Umidade relativa do ar se situa em torno de $85 \%$, sem estações climáticas definidas.

Santos (1997) relata que a vegetação da cidade está representada pelos seguintes tipos de florestas: floresta tropical, capoeira ou de terra firme, e de várzeas e floresta de igapó.

Os solos da várzea onde se situa o igarapé apresentam má drenagem, são argilosos e úmidos, porém, ficam encharcados somente no inverno e apresentam $\mathrm{pH}$ neutro na sua parte superior, sendo estas várzeas do tipo "várzea de maré", pois se enriquecem continuamente com os depósitos deixados pelas marés. O solo por se tratar de uma bacia urbanizada apresenta baixa permeabilidade. Entretanto, existem áreas de permeabilidade considerável, tornando imprescindível o uso do mapeamento para subdividir áreas heterogêneas em parcelas mais homogêneas.

O igarapé está completamente assoreado devido às ocupações clandestinas de famílias que não tinham pra onde ir e que, em grande parte, vieram do interior do estado, ocuparam as terras que eram em sua grande maioria pertencentes à Santa Casa de Misericórdia do Pará e à Universidade Federal do Pará, que possuíam grandes áreas não edificadas que foram invadidas, desde a década de 60.

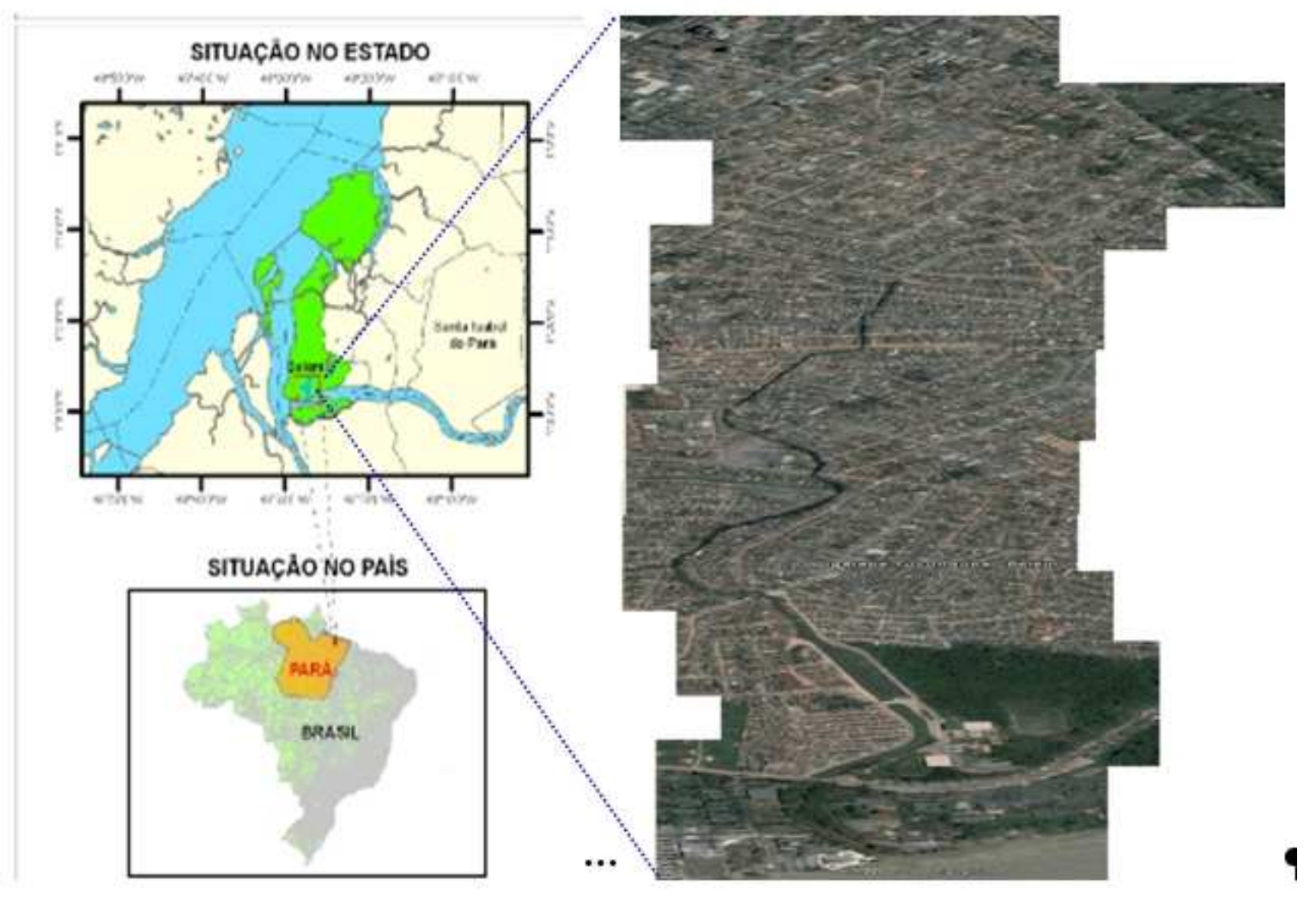

Figura 1: Mapa de localização da Bacia do Igarapé Tucunduba. 


\subsection{Métodos utilizados para pesquisa}

A evolução da ocupação urbana e da conseqüente redução das áreas florestais foi analisada pela comparação das ortofotos retificadas obtidas nos anos de 1972, 1977, 1998 e uma imagem do satélite SPOT de 2006.

O aplicativo computacional Corel Draw X4 V14.0 foi utilizado para elaboração dos mosaicos das diversas imagens que foram exportados e, posteriormente, importados no ArcGIS 9.0 para a interpretação da evolução urbana nas diversas imagens utilizadas.

A maior parte dos solos foram classificados como do tipo D, segundo Tucci et al. (2001) e correspondem aos solos que contêm argilas expansivas, com muito baixa capacidade de infiltração, associados com alto escoamento superficial (Figura 2).

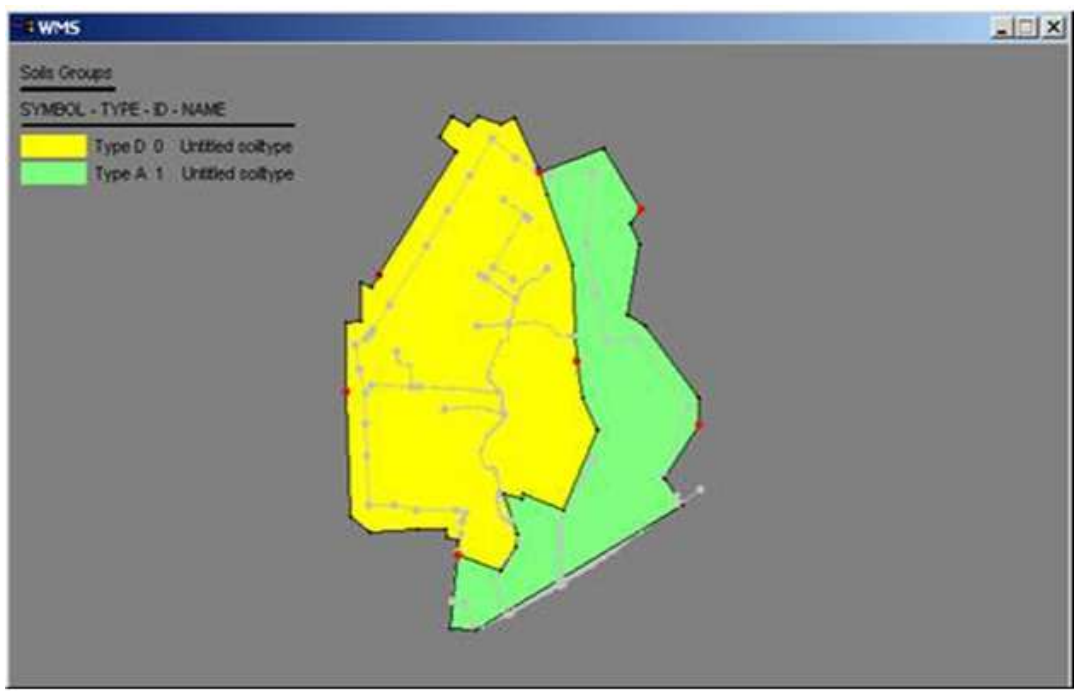

Figura 2. Tipo de solo da Bacia Tucunduba, em amarelo o tipo D e em verde tipo A. Fonte: Cacela Filho et al. (2007).

\section{Resultados e Discussão}

Na Figura 3 tem-se o mapa administrativo gerado pelo programa computacional Arc GIS, onde é possível se verificar a nascente e o exutório do igarapé Tucunduba.

Tucunduba é uma das muitas áreas que compõe a periferia de Belém e que apresenta um posicionamento logístico significativo por estar muito próxima ao centro da cidade, das principais vias de circulação da cidade, além de fazer um elo com o interior do estado, devido seu exutório ser no rio Guamá, onde está instalada a UFPA.

Por toda a extensão do igarapé Tucunduba, desde sua nascente, num dos pontos altos da cidade até seu exutório, no encontro de suas águas com o rio Guamá é notável o adensamento populacional de famílias de baixa renda, morando em palafitas, com estivas construídas pelos próprios moradores, como se fossem ruas o que vem a contribuir para o assoreamento do curso de água. Há insegurança, risco à saúde e conflitos na região, que vem se agravando ao longo do tempo. Hoje, essa área é considerada de grande risco, principalmente, devido ao difícil acesso às ruas dos bairros que compõe o igarapé e por possuir vários becos de fuga.

$\mathrm{Na}$ Figura 4 é possível se verificar a evolução temporal da ocupação e diminuição da área de vegetação. Em 1972 a maior parte das áreas em torno do igarapé era área de vegetação, enquanto que em 2006 o mapa nos mostra uma área mínima de vegetação no campus da Universidade Federal do Pará. 


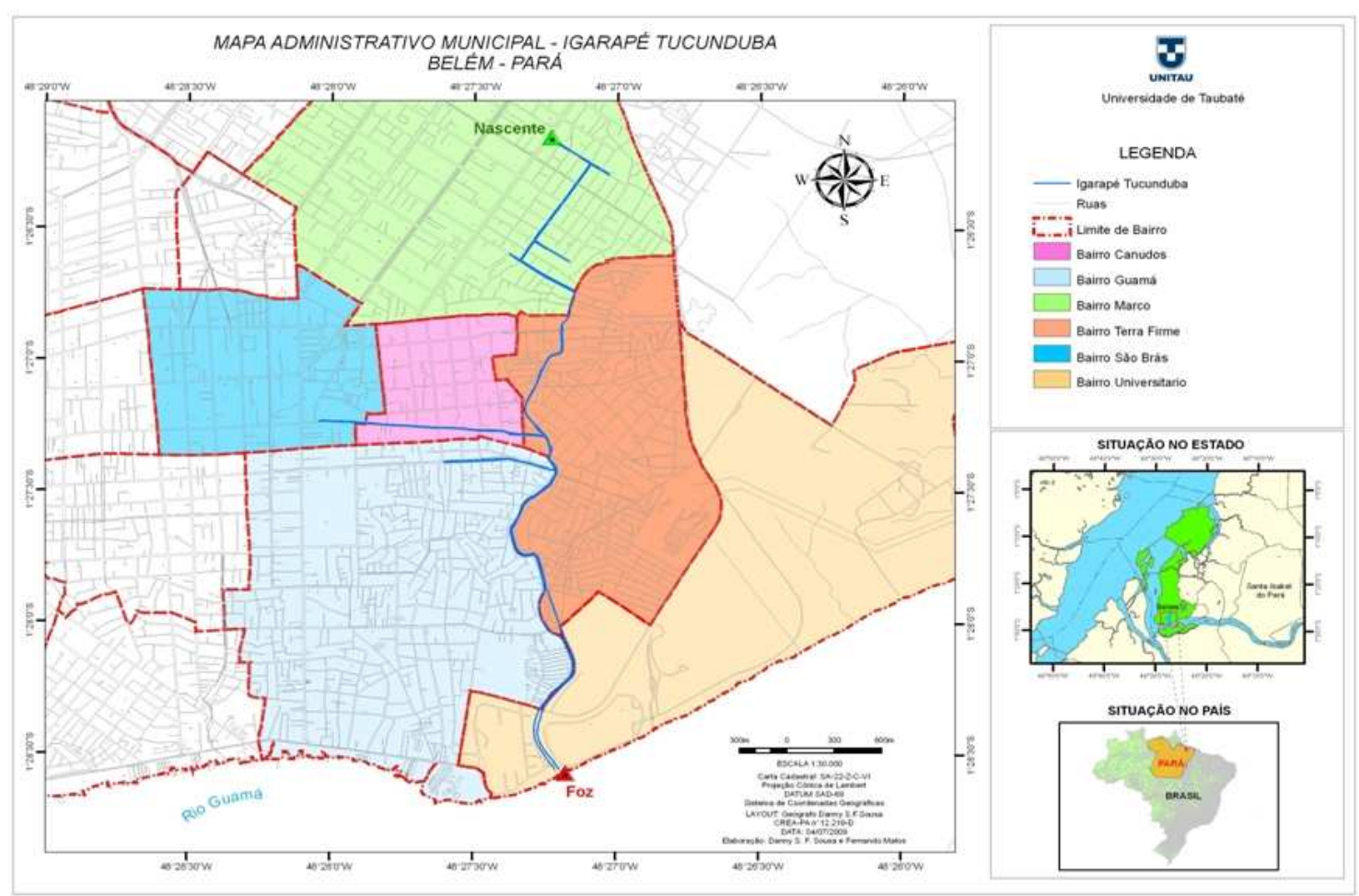

Figura 3: Mapa administrativo municipal mostrando o traçado do igarapé Tucunduba.

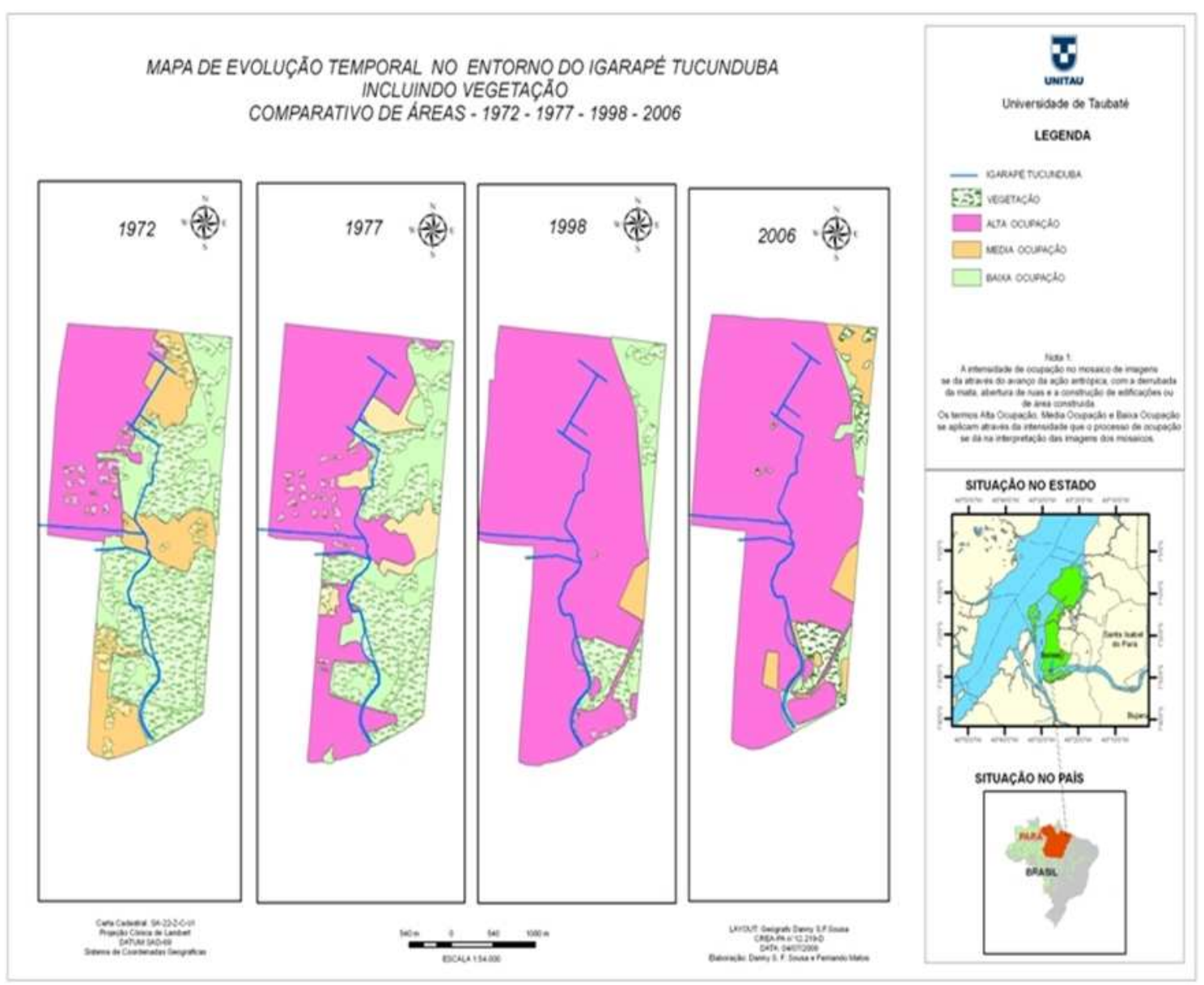

Figura 4: Mapa da ocupação urbana, realçando os remanescentes a vegetação em verde. 
A vegetação densa ou de capoeira alta em 1972, que representa uma área de $3.489 .910 \mathrm{~m}^{2}$ passa a ser de $658.244 \mathrm{~m}^{2}$ em 2006, isto porque parte das terras fazem parte do bairro universitário, onde a Universidade Federal do Pará é a proprietária e preserva essa vegetação. A ausência de vegetação arbórea só não é maior, devido a algumas ações que a UFPA promove, como por exemplo, solicitar, a cada ano, que os ingressantes à universidade plantem uma muda. Isso vem acontecendo desde a década de 90.

Percorrendo-se a várzea do igarapé Tucunduba até suas margens, é possível se observar o acúmulo de resíduos sólidos de diversos tipos (Figuras 5 e 6).

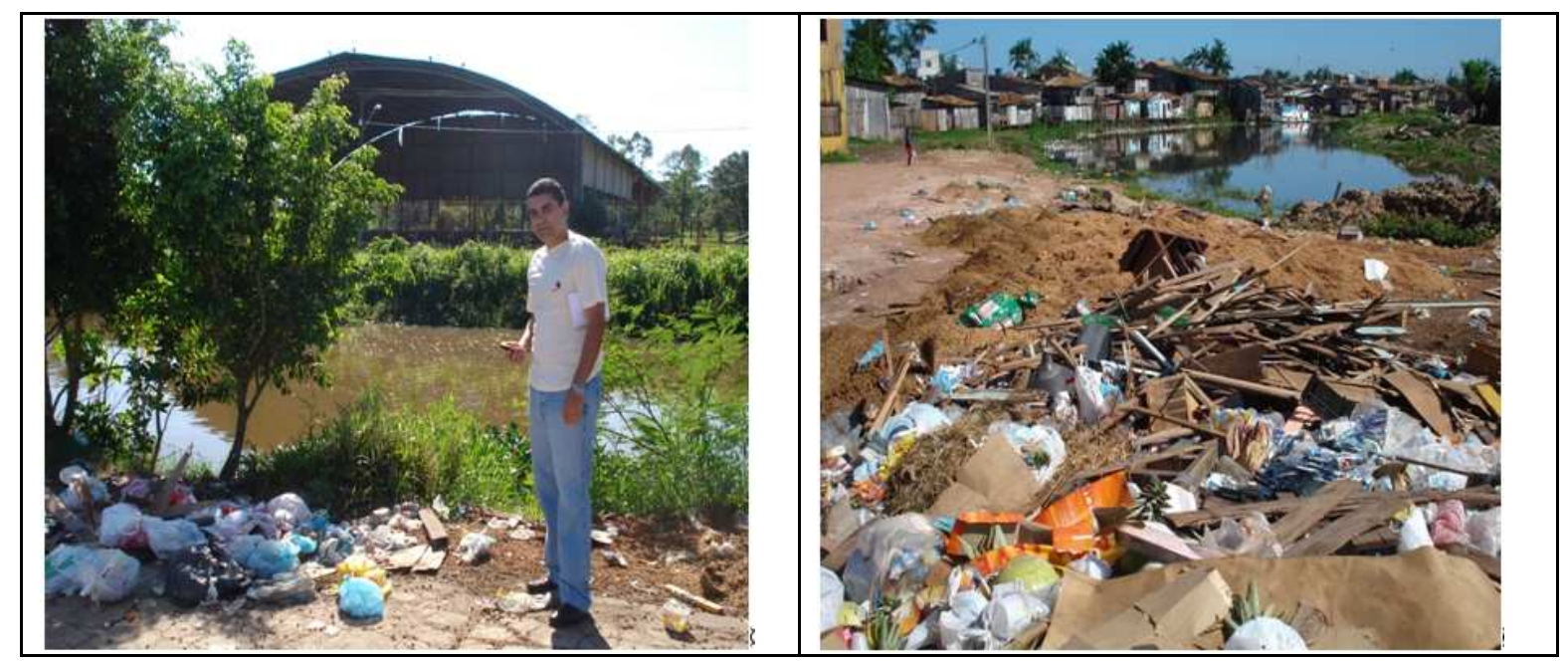

Figura 5: Lixo às margens do igarapé.

Figura 6: Resíduo orgânico e inorgânico à beira do canal.

É possível no igarapé Tucunduba se observar a completa favelização, como mostra a Figura 7, transporte de madeira por meio de embarcações pequenas, insegurança, desmatamento, comércio de carvão, cana de açúcar e açaí nas marginais, de onde seus resíduos são lançados no corpo hídrico. No igarapé já não se encontra mais mata ciliar, pois foram construídas casas, donde é possível se observar que os resíduos de todos os tipos são lançados, diretamente, no igarapé.

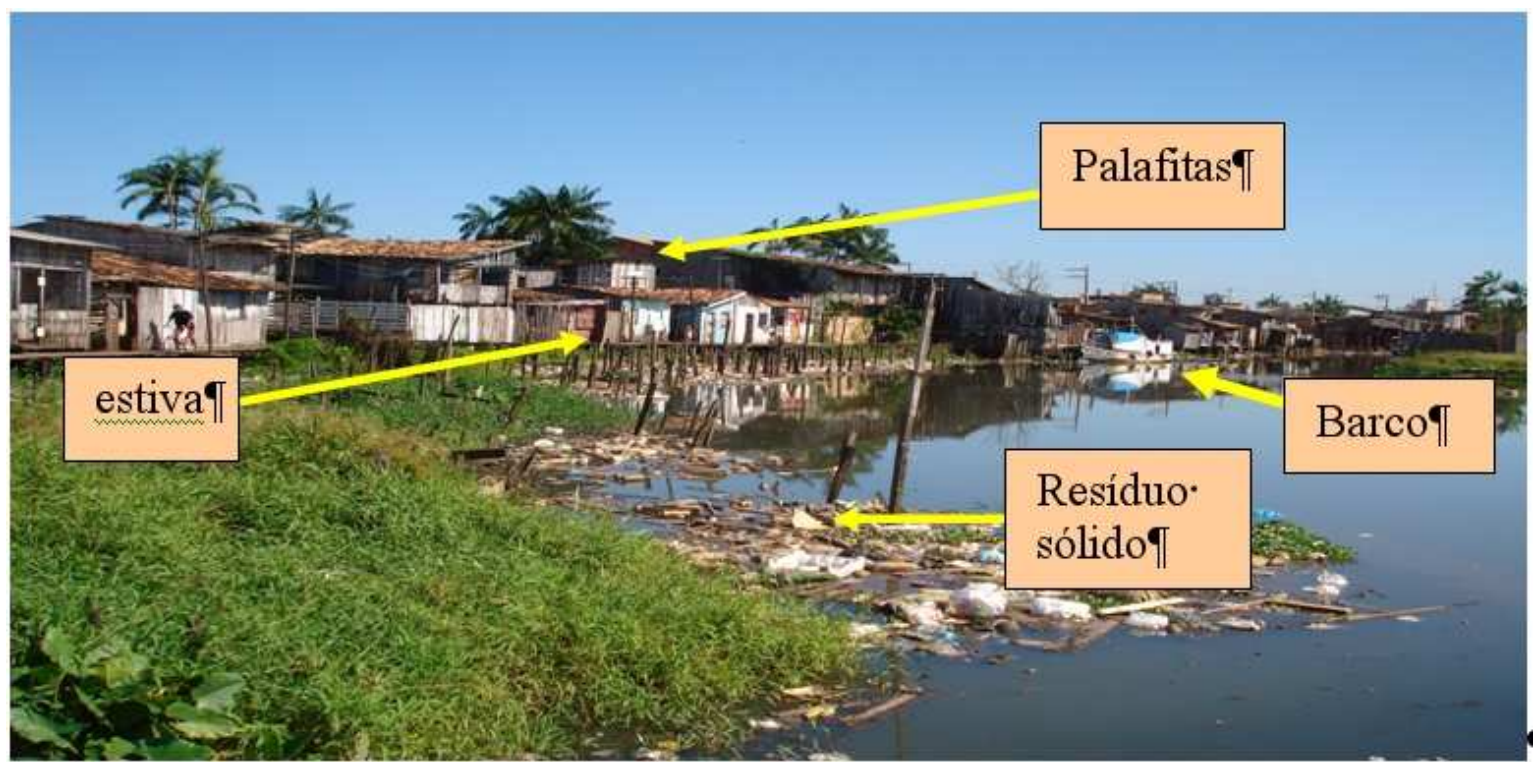

Figura 7: Palafitas e favelização às margens do igarapé. Pequeno barco de transporte de pessoas e produtos e as casas sobre o igarapé, mostrado um ambiente degradado. 


\section{Considerações finais}

Observa-se que a ocupação da área de Preservação Permanente do Igarapé Tucunduba está intimamente ligada à falta de uma política eficiente de habitação para as pessoas que chegam à cidade, bem como a insuficiência de uma política de geração de emprego e renda aos moradores, fazendo com que estes venham a habitar lugares às margens dos mananciais, gerando com isso uma forte degradação ambiental. A urbanização desordenada que se deu em Belém, principalmente, em bairros periféricos, onde se encontram os igarapés causou impactos no corpo hídrico, como assoreamento, desvio no curso do rio, provocado por aterros, desaparecimento da vegetação de várzea, poluição e contaminação da água.

\section{Referências}

CACELA Filho, F. C. O. et al. Modelagem da bacia hidrográfica urbana utilizando o Watershed Modeling System (WMS). In: XIII Simpósio Brasileiro de Sensoriamento Remoto, Florianópolis, Brasil, 21-26 abril 2007, Anais... INPE, p. 3303-3310.

CONAMA. Conselho Nacional do Meio Ambiente. Resolução CONAMA No 001, de 23 de janeiro de 1986. Brasília, Distrito Federal. Disponível em: http://www.lei.adv.br/001-86.htm. Acesso em: jul. 2009.

FERREIRA, C. F. Produção do Espaço Urbano e Degradação a Ambiental: Um Estudo de Caso sobre a Várzea do Igarapé do Tucunduba Belém-Pará. São Paulo, 1995. Dissertação (Mestrado em Geografia Física). Coordenadoria de Pós-Graduação em Geografia Física, Universidade de São Paulo.

GOULART, M. D. C; CALliSTO, M. Bioindicadores de qualidade de água como ferramenta em estudos de impacto ambiental. Minas Gerais, 2003. Revista da FAPAM, ano 2, n 1.

PORTO, M. F. A.. (1995). Aspectos Qualitativos do Escoamento Superficial m Áreas Urbanas. In: TUCCI, C. E. M; PORTO, R. L. L e BARROS, M. T. (Org.). Drenagem Urbana. Porto Alegre: Editora da Universidade.

PREFEITURA MUNICIPAL de BELÉM. Plano de Desenvolvimento Local Riacho Doce e Pantanal. Belém: PMB, 2000.

SANTOS. M. T. P. Avaliação Ambiental da Matéria Orgânica Degradada nos Canais de Drenagem da Região Metropolitana de Belém (PA). Belém, 1997. Dissertação (Mestrado) - Universidade Federal do Pará, Curso de Pós-Graduação em Geologia e Geoquímica.

SILVA, A. M. Gestão de conflitos pelo uso da água em bacias hidrográficas urbanas. Belém 2003. Dissertação de Mestrado apresentada para obtenção do título de Mestre em Engenharia Civil. Área de Concentração: Recursos Hídricos e Saneamento Ambiental. Universidade Federal do Pará. 